\title{
25 Research Soure \\ Effect of Life Satisfaction on Depression Among Childless Married Couples: a Cross-sectional Study
}

\author{
Ju-Young $\mathrm{Ha}$ \\ Pusan National University \\ Hyo-Jin Park ( $\square$ hyojin@pusan.ac.kr) \\ Pusan National University https://orcid.org/0000-0002-9140-0821
}

\section{Research}

Keywords: Depression, Personal satisfaction, Family characteristics, Actor-partner interdependence model

Posted Date: February 10th, 2021

DOI: https://doi.org/10.21203/rs.3.rs-183866/v1

License: @ (i) This work is licensed under a Creative Commons Attribution 4.0 International License. Read Full License

Version of Record: A version of this preprint was published at International Journal of Environmental Research and Public Health on February 12 th, 2022. See the published version at https://doi.org/10.3390/ijerph19042055. 


\section{Abstract}

Background

Depression among childless middle-aged and elderly people is a serious social problem in Korea. However, few studies examine the influence of life satisfaction on the depression of spouses as actors and partners. Hence, this study analyzes the influence of life satisfaction (a positive factor childless married couples may have) on depression.

Methods

This cross-sectional study employed data on couples to analyze the effect of life satisfaction on the depression of childless married couples as actors and partners via the actor-partner interdependence model. The Korea Longitudinal Study of Aging was employed to investigate life satisfaction and depression among 207 childless middle-aged and elderly couples.

Results

Regarding actor effects, wives' $(\beta=-0.285, p=0.004)$ and husbands' $(\beta=-0.403, p<0.001)$ life satisfaction significantly affected individual depression. Regarding partner effects, husbands' life satisfaction $(\beta=-0.255, p=0.011)$ significantly affected wives' depression, and the wives' life satisfaction ( $\beta=$ $-0.375, p<0.001)$ significantly affected husbands' depression.

Conclusions

A childless actor's life satisfaction affected own and partner's depression. Thus, spouses should work together to improve their life satisfaction, thereby improving their depression.

\section{Background}

The middle-aged are in their maturity stage of life, and the elderly can be said to be in their end-of-life stage of life. Such stages mark having completed raising children, developing and passing on cultural norms and values to the next generation, and acknowledging and reflecting on the meaning of life from the vast knowledge and experience gained [1]. In Korea, the middle-aged and elderly account for $55.4 \%$ of the population [2], with an aging rate that is the fastest worldwide. Moreover, the Confucian, patriarchal family system and respect for the elderly remain important in Korean society. Further, the situation of middleaged and elderly groups who experienced the effects of rapid industrialization and modernization is complex [3]. The elderly generation invested all their energy and resources into their children and social development [4]. Given the influence of family values, the family, directly and indirectly, influences individuals' entire lives $[5,6]$. The more satisfactory a spousal relationship, the higher the psychological well-being [7], and the higher the quality of the parentchildren relationship, the higher the life satisfaction [8].

In Korea, the relationship between parents and children is vital since social networks shrink in middle-age and elderly stages, and official duties disappear with retirement, leaving only the informal parenting role intact [9]. A study on the successful retirement scale development of the elderly in Korea identified "a life that is satisfied through child success" as a sub-factor [10]. Thus, Korean parents attach much meaning to how they relate to their children in evaluating their lives [11]. Further, rather than being simply members of a family, children are considered crucial in the cultural aspect of continuing the family line [12]. Moreover, regarding the elderly, the better the communication with adult children, and the more consistent their values, the higher the life satisfaction [8]. Additionally, the more the contact with children, the lower the feeling of depression [13], and the higher the life satisfaction [14].

In Korea, the middle-aged and elderly population group comprises $70 \%$ of depressed patients, with a high rate that increases with age [15]. In particular, the family factor is the influence factor for depression among the middle-aged and elderly [16].

Family characteristics, such as spousal relationships, family support, and cohabitation with children, influence middle-age and elderly depression. Low intimacy between couples and poor parent-children relationships increases loneliness and induces depression [17]. When a family member or spouse lives together [18, 19], with high support of spouse or child, depression is low [20]. Most studies on depression among the middle-age and elderly examine the differences in the presence and absence of cohabitation with children, but few studies examine childless couples.

Spouses and children affect life satisfaction among the middle-aged and elderly. Moreover, individuals are influenced by spouses. Thus, the life satisfaction of childless couples can be evaluated simultaneously via the actor effect that affects an individual and the partner effect that affects a partner in the causal relationship with depression. However, prior studies on the relationship between life satisfaction, depression, and childlessness among the middle-aged and elderly mainly examine individuals.

Per the interdependence theory, couples closely influence each other daily and share various environmental factors and experiences [21]. Therefore, the actorpartner interdependence model (APIM) is useful to analyze the effect of life satisfaction on the depression of childless married couples, and evaluate the bidirectional influence of the couples. Thus, this study aims to (a) evaluate whether there are differences in the level of life satisfaction and depression between male and female dyads of the childless middle-aged and elderly over 45 years old and (b) employ the APIM approach to elucidate and differentiate actor and partner effects of life satisfaction on depression.

\section{Methods}

\section{Participants and study design}

Page $2 / 11$ 
This study employs a cross-sectional approach via the APIM to analyze actor and partner effects of life satisfaction of childless middle-aged and elderly married couples on depression. It also employs data from the seventh Korea Longitudinal Study of Aging (KLoSA) by the Korea Employment Information Service. Out of 1,684 middle-aged and elderly couples (excluding categories of divorce, separation, and bereavement), 207 without children were sampled for analyses. Song and Kim [22] support that a sample ranging from 150 to 400 is appropriate.

\section{Data collection}

KLoSA provides basic data to establish social and economic policies. Given the growing aging trend, KLoSA secures micro-data on the elderly, such as labor supply and retirement, income, consumption behavior, health, and social security system benefits, which are challenging to attain through cross-sectional surveys [23]. The population comprises citizens (excluding Jeju Island) over the age of 45 . The sampling frame was the survey area of the 2005 Population and Housing Census, among which 261,237 ordinary and apartment (excluding island and facility unit) survey areas were set as the extraction unit survey area. The KLoSA survey was conducted in an even-numbered yearly trend from 2006, employing similar survey items as personal interviews. Employing the KLoSA's raw data, questionnaire, and coding book for research means signing up as a member on the survey website (http://survey.keis.or.kr/) of the Korea Employment Information Service, disclosing the purpose of research, and agreeing to comply with the management regulations.

\section{Instruments}

This study employed some of the contents of the seventh KLoSA survey.

\section{Life satisfaction}

KLoSA gauged life satisfaction via the following questions on health status, economic condition, relationship with spouse, relationship with children, and overall quality of life: "How satisfied are you with your health?" "How satisfied are you with your economic status?" "How satisfied are you with your relationship with your spouse?" "How satisfied are you with your relationship with your children?" "How satisfied are you with your overall quality of life (happiness) relative to other people of your age?”

This study excludes "How satisfied are you with your relationship with your children?" because it targets childless middle-aged and elderly couples. All four items were measured on a 10-point Likert scale, the average of which corresponded to life satisfaction level. Corresponding indicators ranged from 0 to 10 points; the higher the score, the higher the life satisfaction. The Cronbach's a reliability coefficient value was 0.87 .

\section{Depression}

Depression was measured via the Center for Epidemiologic Studies Depression (CES-D) 10; the Korean CES-D 10 was abbreviated and employed in the US CES-D 20 items developed for chronically ill elderly patients. Out of 10 questions, 3 catered for depression; 2, positive emotion; 3, somatic symptom; and 2, interpersonal relationship. Each question was measured on a four-point Likert scale. "I thought that kind of thing for a while, or I didn't think that way (less than a day)" was scored 0, "I sometimes thought that way (about a day or two)" was scored 1, "I often thought that way (about 3 to 4 days)" was scored 2 , and "I often thought that way (about 5 to 7 days)" was scored 3 . The combined depression score ranges from 0 to 30 ; the higher the measurement score, the higher the degree of depression. Among the sub-areas, two positive emotions were reverse-coded and used as reverse scoring items. The Cronbach's a reliability coefficient value was 0.88 .

\section{Demographic characteristics of the couples}

Data on the demographic characteristics of couples, such as age, education, perceived economic status, and economic activity, were obtained via the KLoSA survey.

\section{Statistical analysis}

The data collected were analyzed using the Statistical Package for Social Sciences (SPSS) 22.0 and Analysis of Moment Structures (AMOS) 25.0. Participants' demographic characteristics and couples' measurement variables were presented via SPSS descriptive statistics to measure the skewness and kurtosis and test the data normality.

Moreover, the study employed Pearson's correlation coefficients to check the correlation and multicollinearity of each factor and the measurement variables. It employed the AMOS structural equation model to identify the actor and partner effects of the life satisfaction of childless middle-aged and elderly couples on their depression. We chose the structural equation model because it can statistically compare and evaluate the magnitudes of the estimates obtained through model verification.

Further, confirmatory factor analysis (CFA) was conducted to investigate the validity of the latent variables for the model. The fit of the model was evaluated using absolute goodness-of-fit and incremental fit indices. The former included chi-square test $\left(\chi^{2}\right), \chi^{2} / d f$, root-mean-square error of approximation (RMSEA), standard root-mean-square residual (SRMR), goodness-of-fit index (GFI), and adjusted goodness-of-fit (AGFI). The latter included the incremental fit index, 
comparative fit index (CFI), normed fit index (NFI), incremental fit index (IFI), and Tucker-Lewis index (TLI). Finally, bootstrapping in AMOS was employed to verify the statistical significance of the paths in the structural equation model.

\section{Results}

\section{Demographic characteristics of childless middle-aged and elderly couples}

Table 1 presents the demographic characteristics of childless middle-aged and elderly couples. The average ages were 69.43 (66.19) years for husbands (wives). High school graduates were highest among husbands at $42.3 \%$; followed by elementary school graduates and lower at $29.0 \%$; and middle school graduates, $16.9 \%$. Among wives, $42.0 \%$ were elementary school graduates and lower; $34.3 \%$, high school graduates; and $17.9 \%$, middle school graduates. Among the couples participating in the study, 48.3\% (33.3\%) of husbands (wives) engaged in economic activities. Regarding their economic activity, most fell under dual-unemployed at 41.5\%; single-income, 35.3\%; and dual-income, $23.2 \%$. On the subjective economic level, $52.7 \%$ (53.1\%) of husbands (wives) answered "low."

Table 1 Demographic characteristics of couples $(n=207$ couples)

\begin{tabular}{|c|c|c|c|c|}
\hline & & Couples & Wives & Husbands \\
\hline & & $\mathrm{n}(\%)$ & $n(\%)$ & $n(\%)$ \\
\hline \multirow[t]{6}{*}{ Age (years) } & Range & & $57-90$ & $57-91$ \\
\hline & $\mathrm{M} \pm \mathrm{SD}$ & & $66.19 \pm 7.50$ & $69.43 \pm 7.95$ \\
\hline & $\leq 64$ & & $101(48.8)$ & $68(32.9)$ \\
\hline & $65-74$ & & $69(33.4)$ & $85(41.1)$ \\
\hline & $75-84$ & & $33(15.9)$ & $46(22.2)$ \\
\hline & $\geq 85$ & & $4(1.9)$ & $8(3.8)$ \\
\hline \multirow[t]{4}{*}{ Education } & $\leq$ Elementary & & $87(42.0)$ & $60(29.0)$ \\
\hline & Middle & & $37(17.9)$ & 35 (16.9) \\
\hline & High & & $71(34.3)$ & $88(42.5)$ \\
\hline & $\geq$ College & & $12(5.8)$ & $24(11.6)$ \\
\hline \multirow[t]{3}{*}{ Perceived economic status } & High & & $3(1.4)$ & $5(2.4)$ \\
\hline & Medium & & $94(45.4)$ & $93(44.9)$ \\
\hline & Low & & $110(53.1)$ & 109 (52.7) \\
\hline \multirow[t]{5}{*}{ Economic activity } & Yes & & 69 (33.3) & $100(48.3)$ \\
\hline & No & & $138(66.7)$ & 107 (51.7) \\
\hline & Dual-income & $48(23.2)$ & & \\
\hline & Single-income & $73(35.3)$ & & \\
\hline & Dual-unemployed & $86(41.5)$ & & \\
\hline $\mathrm{M} \pm \mathrm{SD}=$ mean \pm standard $\mathrm{d}$ & viation & & & \\
\hline
\end{tabular}

\section{Life satisfaction and depression of male and female dyads}

As Table 2 shows, wives had lower life satisfaction than husbands (5.83 vs. $5.95 ; p=0.012)$. Moreover, wives had higher depression than husbands $(7.28$ vs. 7.04; $p<0.001)$. Further, regarding the subscales of depression, wives had higher or similar scores than husbands in all domains of depression. 
Table 2

Level of life satisfaction and depression among childless middle-aged and

\begin{tabular}{|lllll|}
\hline \multicolumn{5}{c}{ elderly couples ( $\mathrm{n}=207$ couples) } \\
\hline Variables & Wives & Husbands & t value & p-value \\
\hline Life satisfaction & $5.83 \pm 1.45$ & $5.95 \pm 1.46$ & 5.94 & 0.012 \\
Health state & $5.38 \pm 1.81$ & $5.49 \pm 1.97$ & -2.07 & 0.039 \\
\hline Economic state & $5.37 \pm 1.76$ & $5.33 \pm 1.80$ & -1.04 & 0.069 \\
\hline Spouse satisfaction & $6.41 \pm 1.77$ & $6.77 \pm 1.75$ & 6.650 & $<0.001$ \\
\hline Overall quality of life & $6.14 \pm 1.74$ & $6.20 \pm 1.69$ & -8.75 & $<0.001$ \\
\hline Depression & $7.28 \pm 6.05$ & $7.04 \pm 6.48$ & -1.43 & $<0.001$ \\
\hline Depressive emotion & $1.76 \pm 2.13$ & $1.70 \pm 2.41$ & -8.57 & $<0.001$ \\
\hline Positive emotion & $2.65 \pm 2.04$ & $2.48 \pm 1.98$ & -12.50 & $<0.001$ \\
\hline Somatic symptom & $1.86 \pm 2.21$ & $1.84 \pm 2.47$ & -1.41 & 0.095 \\
\hline Interpersonal relationship & $1.01 \pm 1.42$ & $1.02 \pm 1.45$ & -6.24 & $<0.001$ \\
\hline M \pm SD = mean \pm standard deviation & & & \\
\hline
\end{tabular}

\section{Test of the measurement model}

Before verifying the structural model, CFA via AMOS 25.0 was conducted to verify the validity of the questionnaire items and factors to be incorporated into the structural model. Accordingly, the convergent and discriminant validities were verified, as described below.

Standardized Factor Loadings $(\mathrm{FL})>0.70$, Construct Reliability $(\mathrm{CR})>0.70$, and Average Variance Extracted (AVE) $>0.50$ between the questionnaire and factors verified the convergent validity [24]. Among the items to measure depression, the positive emotions of wives and husbands did not meet the criteria and were, thus, removed. That is, three sub-factors of depression for wives and husbands and four sub-factors of life satisfaction were used in the final analysis to verify conceptual reliability and average variance extraction. Thus, convergent validity was verified above the standard values of 0.70 and 0.50 .

Next, this study verified whether the correlation coefficient between the factors was less than the square root of the AVE of each factor to verify the discriminant validity. Accordingly, the correlation coefficient of all factors was lower than the square root of AVE, verifying the discriminant validity.

Finally, to understand how the measurement variables used in this study account for latent variables, we tested the measurement model regarding the life satisfaction and depression of husbands and wives. The results were as follows: $\chi 2=66.942(p<0.001)$; degree of freedom $(d f)=37 ; \chi 2 / d f=1.762 ; N F I=$ $0.963 ; \mathrm{GFI}=0.950 ; \mathrm{AGFI}=0.900 ; \mathrm{CFI}=0.980 ; \mathrm{IFI}=0.982 ; \mathrm{TLI}=0.966 ; \mathrm{RMSEA}=0.061$; and SRMR $=0.069$. The value of the $\chi 2 / \mathrm{df}$ index is $\leq 3 . \mathrm{SRMR}$ is acceptable if the value is $\leq 0.08$ [25]. RMSEA, which considers both model error and simplicity simultaneously, is appropriate if it is $\leq 0.08$. NFI, the standard $\mathrm{GFI}$, is appropriate if it is $\geq 0.80$. GFI and AGFI values are appropriate if higher than 0.90 [26]. Incremental fit indices, CFI, IFI, and TLI estimates are good if they are $\geq 0.9$, being close to $1[25]$.

\section{Test of the structural model}

Further, to find the actor and partner effects of couples' life satisfaction on depression, the study evaluated the normality of the measured variables before modeling a structural equation. Moreover, to test the univariate normality of the measured variables, we calculated the skewness and kurtosis. The assumption of normal distribution was satisfied because the skewness was $\leq 3$, and kurtosis was $\leq 10$ for both husbands and wives. Additionally, as Table 3 shows, correlations ranged from -0.546 to 0.773 . 
Table 3

Correlation between life satisfaction and depression among childless middle-aged and elder couples ( $n=207$ couples) $p$-value: $<0.05 *,<0.01 * *$

\begin{tabular}{|c|c|c|c|c|c|c|c|c|c|c|c|c|c|c|c|}
\hline & 1 & 2 & 3 & 4 & 5 & 6 & 7 & 8 & 9 & 10 & 11 & 12 & 13 & 14 & 1 \\
\hline \multicolumn{16}{|l|}{$\begin{array}{l}\text { Wives' life } \\
\text { satisfaction }\end{array}$} \\
\hline $\begin{array}{l}1 \text { Health } \\
\text { state }\end{array}$ & 1 & & & & & & & & & & & & & & \\
\hline $\begin{array}{l}2 \text { Economic } \\
\text { state }\end{array}$ & $.59 \star \star$ & 1 & & & & & & & & & & & & & \\
\hline $\begin{array}{l}3 \text { Spouse } \\
\text { satisfaction }\end{array}$ & $.51^{\star \star}$ & $.52^{\star \star}$ & 1 & & & & & & & & & & & & \\
\hline $\begin{array}{l}4 \text { Overall } \\
\text { quality of } \\
\text { life }\end{array}$ & .51 *夫 & $.57^{\star \star}$ & $.62^{\star \star}$ & 1 & & & & & & & & & & & \\
\hline \multicolumn{16}{|l|}{$\begin{array}{l}\text { Wives' } \\
\text { depression }\end{array}$} \\
\hline $\begin{array}{l}5 \text { Depressive } \\
\text { emotion }\end{array}$ & $-.46^{\star \star}$ & $-.28^{\star \star}$ & $-.52^{\star \star}$ & $-.37 \star \star$ & 1 & & & & & & & & & & \\
\hline $\begin{array}{l}6 \text { Positive } \\
\text { emotion }\end{array}$ & $-.24 \star \star$ & $-.18^{\star \star}$ & $-.25^{\star \star}$ & $-.17 *$ & $.20 * *$ & 1 & & & & & & & & & \\
\hline $\begin{array}{l}7 \text { Somatic } \\
\text { symptom }\end{array}$ & $-.51^{\star \star}$ & $-.34 \star \star$ & $-.47^{\star \star}$ & $-.35^{\star \star}$ & $.76^{\star \star}$ & $.19 \star \star$ & 1 & & & & & & & & \\
\hline $\begin{array}{l}8 \\
\text { Interpersonal } \\
\text { relationship }\end{array}$ & $-.36^{\star \star}$ & $-.26^{\star \star}$ & $-.43^{\star \star}$ & $-.25^{\star \star}$ & $.71^{\star \star}$ & .13 & $.68^{\star \star}$ & 1 & & & & & & & \\
\hline \multicolumn{16}{|l|}{$\begin{array}{l}\text { Husbands' } \\
\text { life } \\
\text { satisfaction }\end{array}$} \\
\hline $\begin{array}{l}9 \text { Health } \\
\text { state }\end{array}$ & $.51^{\star \star}$ & $.47^{\star \star}$ & $.32^{\star \star}$ & $.41^{\star \star}$ & $-.44^{\star \star}$ & $-.21^{\star \star}$ & $-.51^{\star \star}$ & $-.44^{\star \star}$ & 1 & & & & & & \\
\hline $\begin{array}{l}10 \text { Economic } \\
\text { state }\end{array}$ & $.44^{\star \star}$ & $.60 * \star$ & $.36 * \star$ & .51 ** & $-.25^{\star \star}$ & -.12 & $-.32 * \star$ & $-.21^{\star \star}$ & $.63^{\star \star}$ & 1 & & & & & \\
\hline $\begin{array}{l}11 \text { Spouse } \\
\text { satisfaction }\end{array}$ & $.35^{\star \star}$ & $.34^{\star \star}$ & $.56^{\star \star}$ & $.40 \star \star$ & $-.41^{\star \star}$ & $-.23^{\star *}$ & $-.40 * *$ & $-.38^{\star \star}$ & $.42^{\star \star}$ & $.40 * \star$ & 1 & & & & \\
\hline $\begin{array}{l}12 \text { Overall } \\
\text { quality of } \\
\text { life }\end{array}$ & $.44^{\star \star}$ & $.49 * \star$ & $.47^{\star \star}$ & $.58^{\star \star}$ & $-.39 \star \star$ & $-.15^{\star \star}$ & $-.46^{\star \star}$ & $-.34^{\star \star}$ & $.57^{\star \star}$ & $.62^{\star \star}$ & $.58^{\star \star}$ & 1 & & & \\
\hline \multicolumn{16}{|l|}{$\begin{array}{l}\text { Husbands' } \\
\text { depression }\end{array}$} \\
\hline $\begin{array}{l}13 \\
\text { Depressive } \\
\text { emotion }\end{array}$ & $-.41^{\star \star}$ & $-.31^{\star \star}$ & $-.44^{\star \star}$ & $-.30 \star \star$ & .71 *夫 & $.19 \star \star$ & $.70 * \star$ & $.63^{\star \star}$ & $-.54^{\star \star}$ & $-.29 \star \star$ & $-.39 * *$ & $-.42^{\star \star}$ & 1 & & \\
\hline $\begin{array}{l}14 \text { Positive } \\
\text { emotion }\end{array}$ & $-.23^{\star \star}$ & -.123 & $-.24 \star \star$ & -.14 & $.19 * \star$ & $.77^{\star \star}$ & $.17^{*}$ & $.14^{*}$ & $-.19 \star \star$ & -.09 & $-.27^{\star \star}$ & -.12 & $.19 * \star$ & 1 & \\
\hline $\begin{array}{l}15 \text { Somatic } \\
\text { symptom }\end{array}$ & $-.40^{\star \star}$ & $-.38^{\star \star}$ & $-.40 \star \star$ & $-.32^{\star \star}$ & $.65^{\star \star}$ & $.15^{\star}$ & $.69 * \star$ & $.57 \star \star$ & $-.55^{\star \star}$ & $-.34 * \star$ & $-.32^{\star \star}$ & $-.40 \star \star$ & $.77^{\star \star}$ & $.14^{\star}$ & 1 \\
\hline $\begin{array}{l}16 \\
\text { Interpersonal } \\
\text { relationship }\end{array}$ & $-.38^{\star \star}$ & $-.24^{\star \star}$ & $-.36^{\star \star}$ & $-.28^{\star \star}$ & $.57^{\star \star}$ & $.17^{*}$ & $.62^{\star \star}$ & $.69 * \star$ & $-.42^{\star \star}$ & $-.19 \star \star$ & $-.33^{\star \star}$ & $-.27^{\star \star}$ & $.69 \star \star$ & $.16^{*}$ & .6 \\
\hline
\end{tabular}

The model has the following characteristics: $\chi 2=66.942(p<0.001), \mathrm{df}=38, \chi 2 / \mathrm{df}=1.762, \mathrm{NFI}=0.963, \mathrm{GFI}=0.950, \mathrm{AGFI}=0.900, \mathrm{CFI}=0.984, \mathrm{IFI}=0.984, \mathrm{TLI}=$ 0.966 , RMSEA $=0.061$, and SRMR $=0.069$. Thus, the model was found to have a good fit, as shown in Table 4.

\section{Impact of life satisfaction on depression at the dyadic level}

Table 4 and Fig. 1 shows the results of the actor and partner effects of couples' life satisfaction on depression. The life satisfaction of wives $(\beta=-0.285, p=$ $0.004)$ and husbands $(\beta=-0.403, p<0.001)$ had a significant effect on individual depression. Husbands' life satisfaction $(\beta=-0.255, p=0.011)$ had a significant effect on wives' depression, and wives' life satisfaction $(\beta=-0.375, p<0.001)$ had a significant effect on husbands' depression. 
Table 4

Effect coefficients for the hypothetical model ( $n=207$ couples)

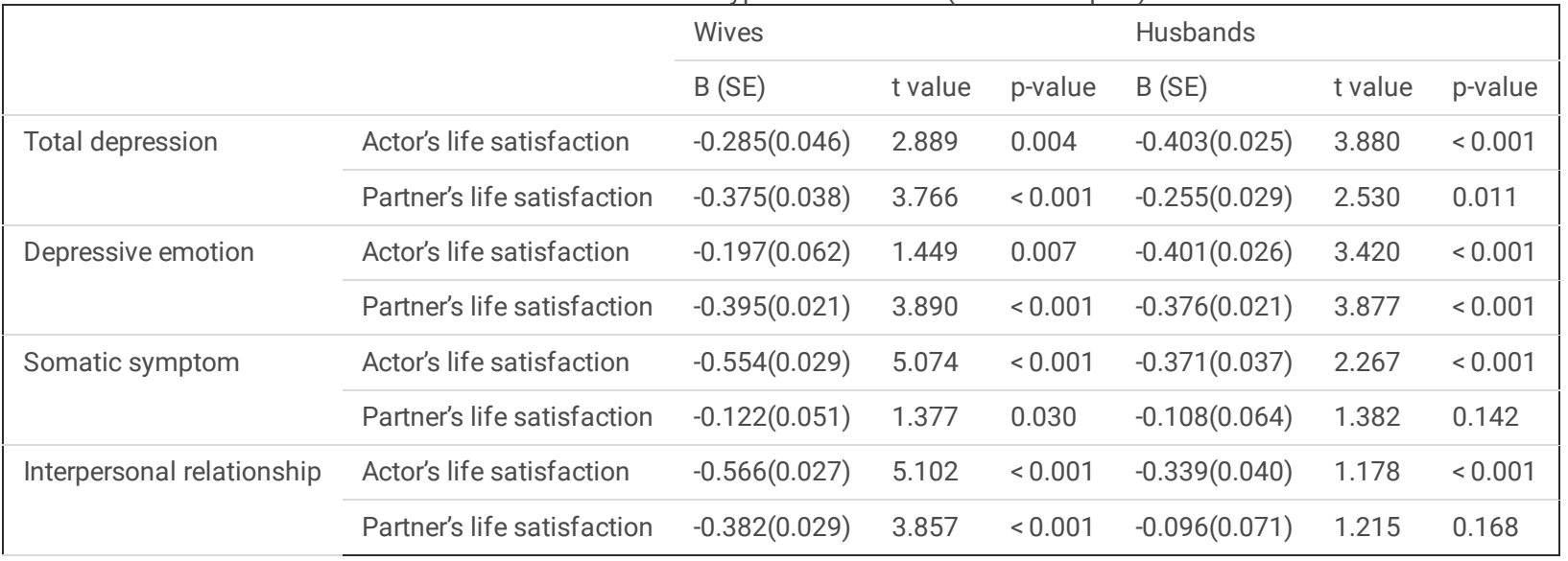

Regarding the effect on the depressive emotion domain, the life satisfaction of wives $(\beta=-0.197, p=0.007)$ and husbands $(\beta=-0.401, p<0.001)$ as actors significantly affected their depressive emotion domain. Regarding partner's life satisfaction, husbands' life satisfaction $(\beta=-0.395, p<0.001)$ significantly affected wives' depressive emotion domain, and wives' life satisfaction $(\beta=-0.376, p<0.001)$ significantly affected husbands' depressive emotion domain.

Regarding the effect on the somatic symptom domain, the life satisfaction of wives $(\beta=-0.554, p<0.001)$ and husbands $(\beta=-0.371$, $p<0.001)$ as actors had a significant effect on their somatic symptom domain. As partners, husbands' life satisfaction $(\beta=-0.122, p=0.030)$ significantly affected wives' somatic symptom domain, whereas wives' life satisfaction $(\beta=-0.108, p=0.142)$ had no significant effect on husbands' somatic symptom domain.

Regarding the effect on the interpersonal relationship domain, the life satisfaction of wives $(\beta=-0.566, p<0.001)$ and husbands $(\beta=-0.339, p<0.001)$ as actors significantly affected their interpersonal relationship domain. As partners, husbands' life satisfaction $(\beta=-0.382, p<0.001)$ significantly affected wives' interpersonal relationship domain, whereas wives' life satisfaction $(\beta=-0.096, p=0.168)$ had no significant effect on husbands' interpersonal relationship domain.

This study examines whether the actor and the partner effects differed between men and women; the two coefficients were considered equal and compared using the chi-square test for the constrained and unconstrained (saturated) models (Table 5). No significant difference was noted between the constrained model, where both the husband and wife's actor effects were constrained equally, and the unconstrained model $(\chi 2=0.344, p=0.557)$. This result reveals that the life satisfaction effect of husband and wife actors had a similar impact on depression. However, there was a significant difference between the constrained model, where the partner effects of husbands and wives were constrained equally, and the unconstrained model $(\chi 2=9.455, p=0.002)$. The findings indicate that the life satisfaction partner effect of husbands significantly impacted depression more than that of wives. Further, there was a significant difference in the equivalence constraints between the actor and partner effects for husbands' life satisfaction $(\chi 2=6.360, p=0.030)$, and that of wives had no significant difference. $(\chi 2=2.988, p=0.084)$. This result reveals that the partner effect of husbands' life satisfaction on depression was more influential than that of wives.

Table 5

X2 Differences in the test between the basic and equivalent constraint models

\begin{tabular}{|c|c|c|c|c|c|c|c|}
\hline Model & $x^{2}$ & df & TLI & CFI & RMSEA & $\Delta x^{2}$ & p-value \\
\hline basic & 66.942 & 38 & .966 & .984 & .061 & & \\
\hline equivalence constraint $1(\mathrm{a}=\mathrm{b})$ & 67.286 & 39 & .973 & .984 & .059 & 0.344 & 0.557 \\
\hline equivalence constraint 2 (a1 = b1) & 76.397 & 39 & .972 & .984 & .060 & 9.455 & 0.002 \\
\hline equivalence constraint $3(\mathrm{a}=\mathrm{b} 1)$ & 73.302 & 39 & .970 & .983 & .062 & 6.360 & 0.030 \\
\hline equivalence constraint $4(b=a 1)$ & 69.930 & 39 & .970 & .982 & .062 & 2.988 & 0.084 \\
\hline
\end{tabular}

$\mathrm{CFI}=$ Comparative Fit Index; $\mathrm{df}$ = Degree of freedom; RMSEA = Root Mean Squared Error of Approximation; TLI = Turker-Lewis Index; a = Husband's actor effects; $b$ = Wives' actor effects; $a 1$ = Husbands' partner effects; $b 1$ = Wives' partner effects

\section{Discussion}

This study aims to understand the actor and partner effects of the life satisfaction of childless middle-aged and elderly couples on depression using data from the seventh KLoSA in 2018. While most prior studies on the middle-aged and elderly regarding the relationship with children, life satisfaction, and depression have been fragmentary or individual studies, this study is the first to assess the relationship between life satisfaction and depression among middle-aged and elderly couples using the APIM approach.

After examining the actor effects of life satisfaction on depression, wives and husbands had actor effects on depression. That is, their life satisfaction significantly affected their depression. These results follow prior studies that verified the negative relationship between life satisfaction and depression in 
middle-aged or elderly individuals $[27,28,29,30]$. Thus, this study indicates that it is essential to improve life satisfaction to lower the depression of childless middle-aged and elderly couples. Particularly, after examining the equivalence constraint model to determine the magnitude of the actor effect of wives and husbands on depression, there was no significant difference. Hence, the life satisfaction of wives and husbands was confirmed to affect their depression negatively.

Further, after examining the partner effect of life satisfaction on depression, the life satisfaction of wives and husbands had a partner effect on depression. That is, the life satisfaction of partners showed a significant effect on the depression of wives and husbands. These results were consistent with prior studies $[31,32,33]$, where depression was related to the difference in spousal influence. Moreover, it is in the same context as the result where the similarity of depression between couples persists over time by measuring the depressive change of couples over 10 years with 905 couples in Belgium via the latent growth model [34]. However, this result is not consistent with Miller et al. [35], where husbands' marital satisfaction did not significantly affect spouses' depression.

However, based on the test of the equivalence constraint model on the partner effect, the size of the partner effect model of wives and the husbands was different in the effect of life satisfaction on depression. In addition, the actor effect model of wives' life satisfaction and that of husbands generated no significant difference. Moreover, the actor effect model of husbands' life satisfaction and that of wives yielded a significant difference. Summarizing the test of the equivalence constraint model, the life satisfaction of wives and husbands affect wives' depression, with no size difference. However, the life satisfaction of husbands and wives can be interpreted to affect husbands' depression, but the life satisfaction of husbands as individual actors has a greater influence than that of wives.

The difference in the partner effects between wives and husbands can be interpreted regarding the difference in empathy per the gender and emotional contagion between couples. According to Hoffman [36], empathic ability is an emotional response to that of others; women showed a higher level of empathy than men. Given that depressive symptoms are feelings of sadness, depression, and droopiness over time, as well as a loss of interest or pleasure in daily activities [37], wives are more concerned with the feelings and moods of spouses than husbands. Having much empathy may affect depression symptoms. Similarly, emotional contagion induces a similar emotion in a person nearby; reportedly, women are more sensitive to the emotions of others than men [38]. Prior studies on emotional contagion mainly examine the transfer of depression; reportedly, such transmission did not significantly affect the level of depression in husbands [39, 40, 41,42]. This study confirmed that life satisfaction of childless middle-aged and elderly couples affected the depression of others; the partner effect of wives and husbands yielded a difference in magnitude. Further research can determine whether the emotional contagion of depression between husband and wife is significant.

Given that this study employed cross-sectional collection data to analyze middle-aged and elderly couples, the generational differences of childless couples could not be identified. Further, there are limitations in explaining causal relationships. Therefore, future studies can investigate the causal relationship between variables through longitudinal data analysis and compare and analyze the generations of childless couples.

In summary, beyond the correlation between life satisfaction and depression of childless middle-aged and elderly couples, actor and partner effects were clearly confirmed. That is, given that the life satisfaction and depression of husbands and wives affect each other, childless middle-aged and elderly couples must be recognized as non-independent beings with mutual relationships rather than individual beings. In addition, in the intervention study to reduce their depression, couples must participate together and actively seek ways to resolve depression by enhancing their life satisfaction.

\section{Conclusions}

This study employed the APIM approach to identify the effect of life satisfaction of childless middle-aged and elderly couples on depression from actor and partner perspectives. The results showed that the life satisfaction of childless middle-aged and elderly couples affected their depression both as actors and partners. This study found that spouses mutually influence each other regarding life satisfaction and depression; thus, it is necessary to develop intervention programs involving couple (not just individual) participation, where they learn to impact each other positively. Regarding the actor effect of life satisfaction, there was no significant difference between husbands and wives, as they affected their depression. However, regarding the partner effect of life satisfaction, the degree to which the husbands and wives affected depression differed. Both couples were affected by the partner effect; even so, the partner effect of wives was greater than that of husbands.

Therefore, it is necessary to improve the life satisfaction of the couple to curb the depression of childless middle-aged and elderly couples. In particular, both the actor and partner effects should be employed to control wives' depression. Further, to control husbands' depression, improving one's own life satisfaction should be prioritized.

The study findings suggest the following areas for future research. First, it is necessary to develop a program for childless middle-aged and elderly couples to participate together and increase their life satisfaction, as the life satisfaction of childless middle-aged and elderly couples positively affects their own depression and that of their partners. Second, it is necessary to analyze the interactions on life satisfaction and depression of childless middle-aged and elderly couples in various cultures using APIM models. The generation of middle-aged and elderly couples in Korea values the tradition of a Confucian and patriarchal family system. Thus, family values relative to different cultures can be compared. Third, it is necessary to compare and analyze life satisfaction and depression of voluntary childless couples and middle-aged and elderly couples. The DINK phenomenon is occurring among dual-income couples of the younger generation. It describes the situation where people voluntarily select no kids for economic stability. Thus, it is necessary to examine life satisfaction and depression relative to middle-aged and elderly couples in the involuntary childless group.

\section{Abbreviations}


KLoSA: Korea Longitudinal Study of Aging

APIM: Actor-partner interdependence model

$\left(\chi^{2}\right), \chi^{2} / d f:$ Chi-square

RMSEA: Root-mean-square error of approximation

SRMR: Standardized root-mean-square residual

GFI: Goodness-of-fit index

AGFI: Adjusted goodness-of-fit index

CFI: Comparative fit index

NFI: Normed fit index

IFI: Incremental fit index

TLI: Tucker-Lewis index

AMOS: Analysis of moment structures

SPSS: Statistical Package for the Social Sciences

DINK: Double Income, No Kids

\section{Declarations}

\section{Ethics approval and consent to participate}

The Ethics Committee of Pusan National University, Busan, Korea, approved this study (PNU IRB/2021_01_HR).

\section{Consent for publication}

Not applicable.

\section{Availability of data and materials}

All data generated or analyzed during this study are included in the published article. For further clarifications, the authors can be contacted at hyojin@pusan.ac.kr.

\section{Competing interests}

The authors declare that they have no competing interests.

\section{Funding}

This research did not receive any specific grant from any agency in the public, commercial, or not-for-profit sector.

\section{Authors' contributions}

JYH contributed to the study design, conception, data analysis, and interpretation. HJP contributed to the study design, conception, data acquisition, and interpretation. All authors read and approved the final manuscript.

\section{Acknowledgments}

Not applicable.

\section{References}


1. Tyler S. Human behavior and the social environment I. USA: University of Arkansas Libraries Publishing Co; 2020. p.1065-252. https://uark.pressbooks.pub/hbse1/.

2. Korean Statistical Information Service. Korea 2019 population and housing census. 2019. https://kosis.kr/search/search.do. Accessed 5 Nov 2020.

3. Hwang NH. A study of the living conditions and welfare needs of the new middle-aged. Korea Institute for Health and Social Affairs Publishing Co; 2019. p.267-74. http://repository.kihasa.re.kr/handle/201002/34620.

4. Kim JH. The experience of ageism and meaning of aging among the Korean elderly by qualitative analysis. Korea J Popul Dev Stud. 2015;38:69-104. http://uci.kci.go.kr/resolution/result.do?res_cd=G704-000152.2015.38.1.002\&res_svc_cd.

5. Oh YJ, Cha KI, Jeon YH. Effect of social support, family support and repulsion-related nursing home use on the well-dying of the elderly. Korean $\mathrm{J}$ Adult Nurs. 2020;32:235-47. https://doi.org/10.7475/kjan.2020.32.3.235

6. Lee SB. A study on purpose in life, family support, death anxiety and well-dying of the elderly. Journal of Learner-Centered Curriculum and Instruction. 2019;19:1263-78. http://dx.doi.org/10.22251/jlcci.2019.19.18.1263.

7. Yoon HS, Yoo HJ. Influences of family relations on successful aging. Korean J Fam Soc Work. 2006;18:5-31. http://uci.kci.go.kr/resolution/result.do? res_cd=G704-000964.2006.18.001\&res_svc_cd.

8. Kim MR. A study of the effect of the factors of successful aging on the life satisfaction of older adults-focusing on the relationship with adult children. Korean J Fam Soc Work. 2017;57:159-182. http://doi.org/10.16975/kjfsw.2017.57.006.

9. Choi HJ, Kim CS. Self-integrity of the elderly and their relationship with children. Korean J Fam Soc Work. 2013;36:89-103. http://uci.kci.go.kr/resolution/result.do?res_cd=G704-000152.2013.36.2.003\&res_svc_cd.

10. Kim MH, Shin KR. The study on the development of the 'successful aging' scale for the Korean elderly. J Korean Gerontolo Soc. 2005;25:35-52. http://uci.kci.go.kr/resolution/result.do?res_cd=G704-000573.2005.25.2.008\&res_svc_cd.

11. Kim MH, Shin KR, Choi HK, Kang MS. The factor of successful aging types in Korean elderly. J Korean Gerontolo Soc. 2006;26:91-104. http://uci.kci.go.kr/resolution/result.do?res_cd=G704-000573.2006.26.1.010\&res_svc_cd.

12. Kim U, Park YS, Kown YE. Intergenerational analysis of family values among Korean mothers: With a specific focus on values of children, socialization attitudes, and support of elderly parents. Korean J Cult Soc Issues. 2005;11:109-42. http://uci.kci.go.kr/resolution/result.do?res_cd=G704000654.2005.11.1.001\&res_svc_cd.

13. Jang YE, Kim SY. The influence of social network with children on depression in older adults. Korean J Soc Welf Res. 2014;39:1-29. http://uci.kci.go.kr/resolution/result.do?res_cd=G704-002139.2014.39..001\&res_svc_cd.

14. Yang OK, Ju SH. An exploratory study on the influencing factors to suicidal ideation among single-household elderly. Ment Health Soc Work. 2011;6:32147. http://uci.kci.go.kr/resolution/result.do?res_cd=G704-000500.2011.37.015\&res_svc_cd.

15. Health Insurance Review \& Assessment Service. Diseases Statistics. 2019. https://www.hira.or.kr/bbsDummy.do? pgmid=HIRAA020045020000\&brdScnBltNo=4\&brdBltNo=2312\&pagelndex=1. Accessed 7 Nov 2020.

16. Kim HK, Sung JM. The longitudinal factors related to the depression of the Korean elderly: Comparison of younger-old and older-old. Korean J Gerontolo Soc. 2014;66:427-49. http://doi.org/10.21194/kjgsw..66.201412.427.

17. Lee SM. Loneliness of old married couples. J Korea Gerontolo Soc. 2005;25:37-54.

18. Kim KS. Factors affecting depression in middle and older people: Focusing on loneliness and laughter index. J Korean Data Anal Society. 2019;21:158598. http://doi.org/10.37727/jkdas.2019.21.3.1585.

19. Kim HK. Comparison of physical, psychosocial and cognitive factors, and depression between middle-aged women and middle-aged men. Korean $\mathrm{J}$ Adult Nurs. 2006;18:446-56. http://uci.kci.go.kr/resolution/result.do?res_cd=G704-000678.2006.18.3.015\&res_svc_cd.

20. Kim CG, Park S. Gender difference in risk factors for depression in community-dwelling elders. J Korean Acad Nurs. 2012;42:136-47. http://dx.doi.org/10.4040/jkan.2012.42.1.136.

21. Hoppmann C, Gerstorf D, Luszcz M. Dyadic interrelations in lifespan development and aging: How does 1+1 make a couple?-Introduction. Gerontolo. 2011;57:144-7. http://doi.org/10.1159/000320324.

22. Song TM, Kim GS. Structural equation modeling for health \& welfare research. Seoul: Hannarae Publishing Co; 2012. p.33-5.

23. Korea Employment Information Service. Korea Longitudinal Study of Ageing. 2018. https://survey.keis.or.kr/klosa/klosa01.jsp. Accessed 5 Nov 2020.

24. Han SS, Lee SC. Nursing and health statistical analysis (using SPSS/Amos). Seoul: Hannarae Publishing Co; 2018. p.372-6. http://uci.kci.go.kr/1410ECN-0101-2018-338-001987637.

25. Hu LT, Bentler PM. Cutoff criteria for fit indexes in covariance structure analysis: conventional criteria versus new alternatives. Struct Equ Model. 1999;6:1-55. https://doi.org/10.1080/10705519909540118.

26. Shevlin M, Miles JN. Effects of sample size, model specification and factor loadings on the GFI in confirmatory factor analysis. Pers Individ Differ. 1998;25:85-90. https://doi.org/10.1016/S0191-8869(98)00055-5.

27. Gigantesco A, Fagnani C, Toccaceli V, Stazi MA, Lucidi F, Violani C, Picardi A. The relationship between satisfaction with life and depression symptoms by gender. Front Psychiatry. 2019;10:1-9. https://doi.org/10.3389/fpsyt.2019.00419.

28. Kim Y, Lee N. The mediating effect of psychological status in the relationship between health characteristics and life satisfaction. Korean J Edu Gerontolo. 2019;5:1-19. https://doi.org/10.31748/KSEG.2019.5.1.1.

29. Cha EJ, Kim KH. Effects of subjective health status on life satisfaction among middle-aged and aged people in Korea: Testing mediating effect of depression. Korean J Gerontolo Soc. 2015;70:53-80. https://doi.org/10.21194/kjgsw..70.201512.53.

Page $10 / 11$ 
30. Jeon HS, Dunkle RE. Stress and depression among the oldest-old: A longitudinal analysis. Res Aging. 2009;31:661-87.

https://doi.org/10.1177/0164027509343541.

31. Heo SY. Longitudinal analyses on contagion of depression of married elderly couples in Korea. Korean J Gerontolo Soc. 2020;75:189-215. https://doi.org/10.21194/kjgsw.75.2.202006.189.

32. Ayotte BJ, Yang FM, Jones RN. Physical health and depression: A dyadic study of chronic health conditions and depressive symptomatology in older adult couples. J Gerontolo B Psychol Sci Soc Sci. 2010;65:438-48. https://doi.org/10.1093/geronb/gbq033.

33. Ruthig JC, Trisko J, Stewart TL. The impact of spouse's health and well-being on own well-being: A dyadic study of older married couples. J Soc Clin Psychol. 2012;31:508-29. https://doi.org/10.1521/jscp.2012.31.5.508.

34. Desai S, Schimmack U, Jidkova S, Bracke P. Spousal similarity in depression: a dyadic latent panel analysis of the panel study of Belgian households. J Soc Clin Psychol. 2012;123:309-14. https://doi.org/10.1037/a0025575.

35. Miller RB, Mason TM, Canlas JM, Wang D, Nelson DA, Hart CH. Marital satisfaction and depressive symptoms in China. J Fam Psychol. 2013;27:677-82. https://doi.org/10.1037/a0033333.

36. Hoffman ML. Sex differences in empathy and related behaviors. Psycholo Bull. 1977;84:712-22. https://doi.org/10.1037/0033-2909.84.4.712.

37. Olfson M, Klerman GL. Depressive symptoms and mental health service utilization in a community sample. Soc Psychiatric Epidemiol. 1992;27:161-7. https://doi.org/10.1007/BF00789000.

38. Hatfield E, Cacioppo JT, Rapson RL. Emotional contagion. Curr Dir Psychol Sci. 1993;2:96-9. https://doi.org/10.1111/1467-8721.ep10770953.

39. Heo SY. Longitudinal analyses on contagion of depression of married elderly couples in Korea. Korean J Gerontolo Soc. 2020;75:189-215. https://doi.org/10.21194/kjgsw.75.2.202006.189.

40. Kouros CD, Cummings EM, Buehler C. Longitudinal association between husbands' and wives' depressive symptoms. J Marriage Fam. 2010;72:135-47. https://doi.org/10.1111/j.1741-3737.2009.00688.x.

41. Monin JK, Levy B, Chen B, Fried T, Stahl ST, Schulz R, Doyle M, Kershaw T. Husbands' and wives' physical activity and depressive symptoms: Longitudinal findings from the cardiovascular health study. Ann of Behav Med. 2015;49:704-14. https://doi.org/10.1007/s12160-015-9705-4.

42. Peek MK, Stimpson JP, Townsend AL, Markides KS. Well-Being in older Mexican American spouses. Gerontologist. 2006;46:258-65. https://doi.org/10.1093/geront/46.2.258.

\section{Figures}

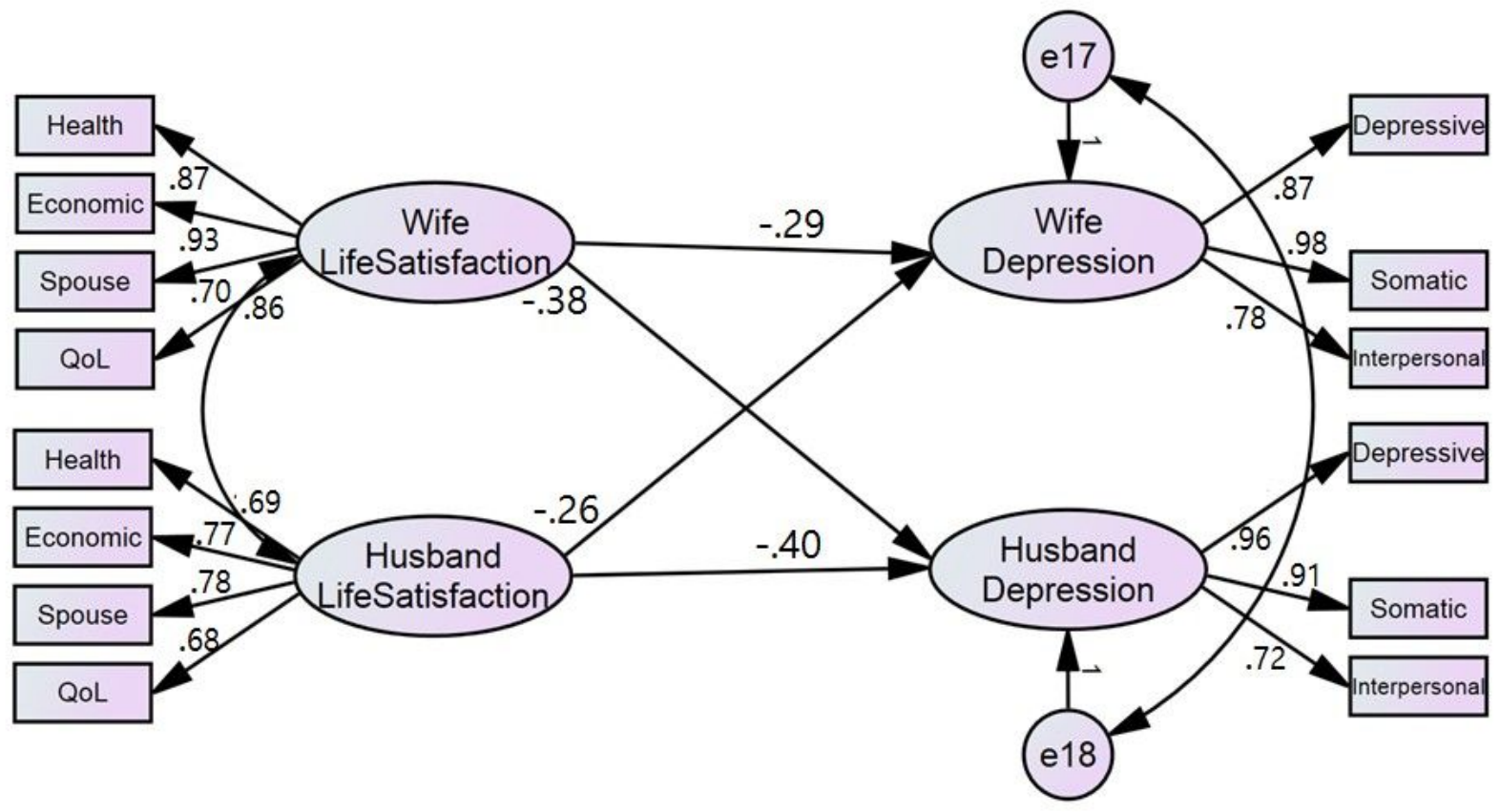

Figure 1

Assessment of the hypothetical model 